\title{
Adjuvant therapy using ex vivo-expanded allogenic natural killer cells in hepatectomy patients with hepatitis B virus related solitary hepatocellular carcinoma: MG4101 study
}

\author{
Jong Man Kim ${ }^{1, *}$, Sung Yoo Cho ${ }^{2, *}$, Jinsoo Rhu', Miyoung Jung ${ }^{2}$, Jung Hyun Her $^{2}$, Okjae Lim², \\ Gyu-Seong Choi ${ }^{1}$, Eui-Cheol Shin ${ }^{3}$, Yu-Kyeong Hwang ${ }^{2}$, and Jae-Won Joh ${ }^{1}$ \\ ${ }^{1}$ Department of Surgery, Samsung Medical Center, Sungkyunkwan University School of Medicine, Seoul, \\ ${ }^{2}$ Cell Therapy Research Center, GC LabCell, Yongin, \\ ${ }^{3}$ Laboratory of Immunology and Infectious Diseases, Graduate School of Medical Science and Engineering, \\ Korea Advanced Institute of Science and Technology, Daejeon, Korea
}

\begin{abstract}
Backgrounds/Aims: Fewer reports have been published regarding hepatectomy patients with solitary hepatocellular carcinoma (HCC) who received immunotherapeutic agents as adjuvant therapy. We evaluated the safety and efficacy of ex vivo-expanded allogenic natural killer (NK) cells in those patients with modified International Union Against Cancer (UICC) stage T3. Methods: From August 2014 to October 2015, five patients who underwent hepatic resection received ex vivo-expanded allogenic NK cells. Patients received five rounds of NK cells $\left(2-3 \times 10^{7} \mathrm{cells} / \mathrm{kg}\right)$ at postoperative 4 , $6,8,12$, and 16 weeks. This study is registered with ClinicalTrials.gov, number NCT02008929. Results: The median age of the five patients (three men and two women) was 44.8 years (range, 36-54 years). All had hepatitis B virus-related $\mathrm{HCC}$, and the median tumor size was $2.2 \mathrm{~cm}$ (range, 2.1-8.2 cm). None of the patients had any adverse events. HCC recurrence developed in two patients at one year after hepatic resection, but four patients were alive at 3 years. The two recurrence-free patients showed a higher ratio of CD8+ $\mathrm{T}$ lymphocyte populations before and after administration of ex vivo-expanded allogenic NK cells compared with the three patients who experienced recurrence. Conclusions: Immunotherapy using ex vivo-expanded allogenic NK cells in hepatectomy patients can be used safely. Further studies should be investigated for efficacy. (Ann Hepatobiliary Pancreat Surg 2021;25:206-214)
\end{abstract}

Key Words: Hepatocellular carcinoma; Natural killer cells; Immunotherapy; Safety; Efficacy

\section{INTRODUCTION}

Liver resection (LR) is a curative treatment method for solitary hepatocellular carcinoma (HCC). ${ }^{1}$ However, the recurrence of HCC after LR is a major surgical limitation because the tumor recurrence rate exceeds $50 \%$ at 5 years after resection. ${ }^{2,3}$ In addition, cases with early $\mathrm{HCC}$ recurrence showed poor survival compared to those with late recurrence. ${ }^{4,5}$

The high incidence of HCC has led to efforts to develop adjuvant therapies to reduce recurrence. A number of studies have explored adjuvant strategies. ${ }^{6}$ A recent multicenter trial that investigated the effect of sorafenib after surgical resection/radiofrequency ablation (RFA) failed to demonstrate any adjuvant effect of sorafenib on survival. ${ }^{7}$ This underlines the need for novel and effective adjuvant therapies to treat patients with HCC and to prevent recurrence after curative liver resection. However, the benefit of any form of adjuvant therapy remains unclear, and current scientific guidelines do not recommend adjuvant therapy in patients treated with resection. ${ }^{8-10}$

Immunotherapy is emerging as a new treatment strategy

Received: September 11, 2020; Revised: October 10, 2020; Accepted: October 11, 2020

Co-Corresponding author: Jae-Won Joh

Department of Surgery, Samsung Medical Center, Sungkyunkwan University School of Medicine, 81 Irwon-ro, Gangnam-gu, Seoul 06351, Korea Tel: +82-2-3410-3466, Fax: +82-2-3410-0040, E-mail: jw.joh@samsung.com

Co-Corresponding author: Yu-Kyeong Hwang

Cell Therapy Research Center, GC LabCell, 107 Ihyeon-ro 30beon-gil, Giheung-gu, Yongin 16924, Korea

Tel: +82-31-260-9853, Fax: +82-31-270-1450, E-mail: ykhwang@greencross.com

*Jong Man Kim and Sung Yoo Cho contributed equally to this work as co-first authors.

Copyright (C) 2021 by The Korean Association of Hepato-Biliary-Pancreatic Surgery

This is an Open Access article distributed under the terms of the Creative Commons Attribution Non-Commercial License (http://creativecommons.org/ icenses/by-nc/4.0) which permits unrestricted non-commercial use, distribution, and reproduction in any medium, provided the original work is properly cited. Annals of Hepato-Biliary-Pancreatic Surgery • pISSN: 2508-5778 - eISSN: 2508-5859 
following surgery in HCC patients. Immunotherapy has the potential to offer systemic, nontoxic, and durable antitumor effects, and therefore is highly attractive as a treatment option for HCC. Adoptive cell therapy is a highly personalized form of passive immune therapy based on the infusion of autologous or allogenic cells that are activated and expanded ex vivo. Previous studies using immunotherapy reported high response rates. ${ }^{11-13}$ Most of these studies are being carried out using modified T-cells, but we are increasingly interested in a similar adaptation of the immune system's "natural killer", or NK cells, which are able to attack cancer cells directly and quickly. Recently, the development of allogenic NK cells has gained much attention because interaction of the relevant self-major histocompatibility complex (MHC) class I molecules with a given killer cell immunoglobulin-like receptor (KIR) in an autologous setting results in inhibition of the effector functions of autologous NK cells, even in the presence of additional activation signals. ${ }^{14}$ Indeed, in a recent clinical trials, infusion with allogenic NK cells has been shown to elicit more potent antitumor efficacy than with autologous NK cells in various cancers, such as acute myeloid leukemia, renal-cell carcinoma, malignant melanoma, lung cancer, and hepatic cancer. ${ }^{15}$ To this end, we established an efficient method for the large-scale, ex vivo-expansion of NK cells from peripheral blood mononuclear cells (PBMC) acquired from random healthy donors under good manufacturing practice (GMP) conditions. These ex vivo-expanded, random healthy donor-derived allogeneic NK cells, defined as MG4101, previously showed antitumor potency and safety in preclinical and phase I clinical studies, respectively. ${ }^{16,17}$

In the present study, we aimed to evaluate the safety and efficacy of adjuvant immunotherapy using ex vivo-expanded allogenic NK cell infusion in hepatectomy patients, who had no evidence of residual tumors, after curative liver resection.

\section{MATERIALS AND METHODS}

\section{Patients}

Patients who had undergone curative liver resection as a treatment for HCC of modified UICC stage III were screened for this study. ${ }^{10}$ The diagnosis of HCC was made by histological examination. The inclusion criteria were: age more than 20 years and less than 70 years, Child-Pugh class A, patients who underwent curative liver resection, modified UICC stage III, and patients who agreed to participate in the clinical trial. Any patients with evidence of extrahepatic metastasis; ruptured HCC; a history of RFA, transarterial chemoembolization (TACE), radiation, or percutaneous ethanol injection (PEI); evidence of infection; a history of cardiovascular disease such as coronary artery disease, cardiac arrhythmia, congestive heart failure, angina pectoris, or myocardial infarction; autoimmune disease; or a history of malignancy except HCC within the 5 years prior to screening; female patients who were pregnant or lactating; and any patients who received steroids or immunosuppressants within the 4 weeks prior to screening were excluded.

\section{Study design}

This phase II clinical study was a prospective, open-labelled trial. The study was conducted at Samsung Medical Center, Seoul, Republic of Korea. All patients provided written informed consent prior to enrollment in this study. The study protocol and procedures were approved by the Institutional Review Board at Samsung Medical Center (SMC-2013-04-019). All methods and procedures associated with this study were conducted in accordance with the principles of the Declaration of Helsinki and local law. This study is registered with ClinicalTrials.gov, number NCT02008929.

Patients who provided informed consent were screened within 2 weeks following curative liver resection and before the start of immunotherapy. Patients received five treatments with ex vivo-expanded allogenic NK cells over 12 weeks (three treatments every 2 weeks followed by two treatments every 4 weeks). Amounts of $2-3 \times 10^{7}$ cells $/ \mathrm{kg}$ were administered to patients for 30 minutes. Patients received antihistamine for prophylaxis before NK cell infusion (Fig. 1).

\section{Preparation and expansion of NK cells}

PBMCs were isolated from random healthy donors, and NK cells were expanded as described previously under the conditions of GMP at Green Cross LabCell Corp. ${ }^{17}$ Briefly, $\mathrm{CD}^{+}$T-cell-depleted PBMCs were expanded at a seeding concentration of $2 \times 10^{5}$ cells $/ \mathrm{ml}$ in CellGro SCGM serumfree medium (CellGenix) with $1 \%$ auto-plasma, $1 \times 10^{6}$ cells $/ \mathrm{ml}$ 


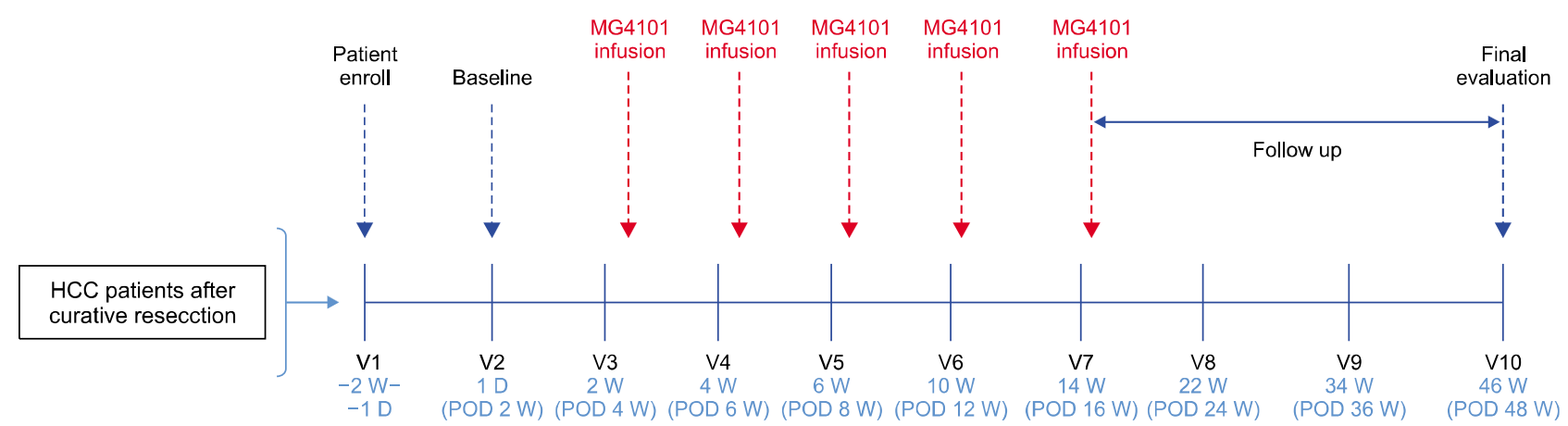

Fig. 1. Study design for MG4101 infusion and evaluation during follow up period.

irradiated (2,000 rad) autologous PBMCs, $10 \mathrm{ng} / \mathrm{ml}$ of monoclonal antibody to CD3 (OKT3; Orthoclon), and 500 $\mathrm{IU} / \mathrm{ml}$ of IL2 (Proleukin) in an A-350N culture bag (NIPRO). NK cells were fed fresh medium with 500 IU/ml of IL2 every 2 days until they were harvested on day 14. After expansion, the cytotoxicity of MG4101 was evaluated by flow cytometric cytotoxicity assay against K562, SNU387 and Huh7 as described. ${ }^{17}$ K562 and SNU387 were obtained from the ATCC and cultured in RPMI-1640 medium (GIBCO) supplemented with 10\% fetal bovine serum (FBS) (GIBCO). Huh7 was obtained from the Korean Cell Line Bank and also cultured in RPMI-1640 medium (GIBCO) supplemented with 10\% FBS (GIBCO).

\section{Flow cytometric analysis of NK cells}

The phenotype of expanded NK cells was analyzed by flow cytometry. NK cells were stained with the appropriate monoclonal antibodies as follows: anti-CD56-PE-Cy5 (B159), anti-CD3-FITC (UCHT1), anti-CD16 (3G8), antiCD14 (M5E2), anti-CD19 (HIB19), anti-NKp30-PE (P30-15), anti-NKp44-PE (P44-8.1), anti-NKp46-PE (9E2/NKp46), anti-CD226-PE (DX11), anti-CD25-PE (M-A251), anti-CD132PE (AG184), anti-CD57-PE (NK-1), anti-CXCR3-PE (1C6/ CXCR3) (BD Biosciences), anti-NKG2A-PE (131411), anti-NKG2C-PE (134591), anti-NKG2D-PE (149810), antiCD69-PE (298614), anti-NKp80-PE (239127), anti-CD122PE (27302) (R\&D), anti-CD96-PE (NK92.39), anti-CD161PE (HP-3G10), anti-CD62L-PE (DREG-56) (eBioscience), and anti-CD244-PE (C1.7) (Beckman Coulter) Samples were acquired on a BD FACS Canto II or LSR Fortessa and data were analyzed using FlowJo software (TreeStar Inc., Oregon).

\section{Immune monitoring of recipients}

Flow cytometric analysis of the change in immune cell populations after MG4101 administration was performed on PBMCs that were serially acquired from recipients. Various immune cells including $\mathrm{T}$ cells $(\mathrm{CD} 3+\mathrm{CD} 4+, \mathrm{CD} 3+$ CD8+), B cells (CD19+, CD20+), NK cells (CD3-CD56+, CD56+CD16+), regulatory $\mathrm{T}$ cells (Treg, CD4+CD25bright Foxp3+CD127dim) and myeloid-derived suppressor cells (MDSC, Lin-CD14-HLA-DR-CD11b+CD15+) were analyzed by Flow cytometry as described. ${ }^{16}$ Multiple cytokines and chemokines in patient plasma were quantified with commercially available cytometric bead-based assays according to the manufacturers' instructions (FlowCytomix; eBioscience).

\section{Surveillance and outcomes}

The procedures used for surveillance after liver resection have been described previously. ${ }^{2}$ All patients were checked every two or three months in the second postoperative year and every 6 months in subsequent years. Tumors were evaluated by tumor markers such as alpha-fetoprotein (AFP) and protein induced by vitamin $\mathrm{K}$ absence/antagonism-II (PIVKA-II) and radiologic evaluations such as contrast-enhanced computed tomography or magnetic resonance imaging every 3 months for 24 months and then every 3-6 months thereafter. Relapse-free survival (RFS) was defined as the interval between the hepatectomy data and the recurrence date or last follow-up date, while overall survival (OS) was defined as the interval between the hepatectomy data and the death date or last follow-up date. Follow-up time was the length of time from surgery to final follow-up or death. 


\section{Statistics}

All statistical analyses were performed using SPSS ver. 22.0 (SPSS, Inc., IBM Corporation, Armonk, NY, USA). Continuous variables are described as median with range. Categorical variables are expressed as number and percentage of subjects. RFS and OS were evaluated with Kaplan-Meier curves using the log-rank test. All tests were two-tailed, and statistical significance was defined as $p<0.05$.

\section{RESULTS}

\section{Patient characteristics}

Between 11 August 2014 and 14 December 2015, five patients were screened and enrolled into this study after having met the eligibility criteria. None of the patients had a history of locoregional therapy prior to surgery. Three patients were male, and The median age was 45 years (range, 36-54). All patients had hepatitis B virus-related HCC, a performance status of 0 , and Child-Pugh class A. Median AFP and PIVKA-II were $56.7 \mathrm{mg} / \mathrm{dl}$ (range, 11.2-9784.4 mg/dl) and $43 \mathrm{mAU} / \mathrm{ml}$ (range, 24-2596 mAU/ml), respectively. Three patients received Entecavir and two received Tenofovir as antiviral agents.

Clinical characteristics are summarized in Table 1. Three patients underwent major liver resection. Median operation time was 197 minutes (range, 172-235 minutes), and median blood loss was $200 \mathrm{ml}$ (range, 50-600 ml). None developed complications or required transfusion with red blood cells during the surgical procedure and postoperative period. All patients had solitary HCC with a median tumor size of $2.2 \mathrm{~cm}$ (range, 2.1-8.2 cm). Microvascular invasion was seen in all patients, but portal vein tumor thrombosis was seen in only one patient.

\section{Characteristics of allogeneic, and ex vivo- expanded NK cells}

All patients were administered ex vivo-expanded allogenic NK cells during five cycles. The infusion schedule of NK cells is outlined in Fig. 2. As shown in Fig. 2A, the purity of allogeneic, expanded NK cells (CD3 ${ }^{-}$ $\mathrm{CD}^{+} 6^{+}$) was $98.48 \pm 1.46 \%$ with minimal contamination (less than $1 \%$ ) of $\mathrm{CD}^{+} \mathrm{T}$ cells $(0.57 \pm 0.48 \%), \mathrm{CD}^{+}$ monocytes $(0.76 \pm 0.4 \%)$, or $\mathrm{CD} 19^{+} \mathrm{B}$ cells $(0.01 \pm 0.02 \%)$. Expanded NK cells exerted strong cytotoxic activity against K562, an NK-sensitive target, and also showed a highly cytotoxic effect against the SNU387 and Hur7 hepatocellular carcinoma cell lines (Fig. 2B). The surface expression of activating or inhibitory NK receptors was analyzed. Functional markers such as CD16 and NKG2D were highly expressed in expanded NK cells. Expression of activating receptors NKG2C, NCRs, 2B4 (CD244), and DNAM-1 (CD226) was high, while expression of inhibitory receptor NKG2A was low. CD25, CD62L, and CD69 showed activation status of the expanded NK cells as described (Fig. 2C).

\section{Safety}

Mild adverse events developed in only one patient who showed wound seroma discharge in the incisional area. Across all patients, every infusion was well-tolerated and unassociated with any acute or delayed toxicities. None of the subjects showed drug-related adverse reactions and thus toxicity-related suspension of the MG4101 injection did not occur during our study. There were no increases in aspartate transaminase (AST), alanine transaminase (ALT), alkaline phosphatase (ALP), total bilirubin, international normalized ratio (INR) or HBV DNA after any of the infusions.

Table 1. Baseline patient characteristics

\begin{tabular}{|c|c|c|c|c|c|c|c|c|c|c|}
\hline No. & $\begin{array}{l}\text { Age } \\
\text { (years) }\end{array}$ & Gender & $\begin{array}{l}\text { Platelet } \\
(\times 1,000)\end{array}$ & $\begin{array}{c}\text { Total } \\
\text { bilirubin } \\
(\mathrm{mg} / \mathrm{dl})\end{array}$ & INR & $\begin{array}{c}\text { HBV } \\
\text { DNA } \\
(\mathrm{IU} / \mathrm{ml})\end{array}$ & $\mathrm{HBeAg}$ & $\begin{array}{c}\text { AFP } \\
(\mathrm{mg} / \mathrm{dl})\end{array}$ & $\begin{array}{l}\text { PIVKA-II } \\
(\mathrm{mAU} / \mathrm{ml})\end{array}$ & $\begin{array}{c}\text { ICG-R15 } \\
(\%)\end{array}$ \\
\hline 1 & 36 & $\mathrm{~F}$ & 200 & 0.8 & 0.98 & 124 & Negative & 9784.4 & 2596 & 4.6 \\
\hline 2 & 44 & M & 237 & 0.8 & 0.99 & 0 & Negative & 56.7 & 24 & 15.8 \\
\hline 3 & 44 & M & 237 & 1.1 & 0.99 & 206 & Positive & 61.3 & 59 & 9.2 \\
\hline 4 & 54 & M & 161 & 0.9 & 0.98 & 0 & Positive & 21.9 & 43 & 10.2 \\
\hline 5 & 45 & $\mathrm{~F}$ & 169 & 0.6 & 1.11 & 0 & Negative & 11.2 & 38 & 3.7 \\
\hline
\end{tabular}

INR, international normalized ratio; AFP, alpha-fetoprotein; PIVKA-II, protein induced by vitamin K absence/antagonism-II; ICG-R15, indocyanine green retention rate at $15 \mathrm{~min}$ 
A

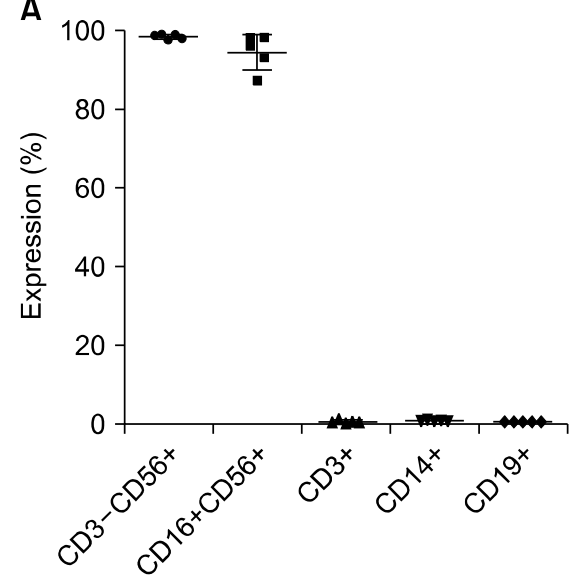

C

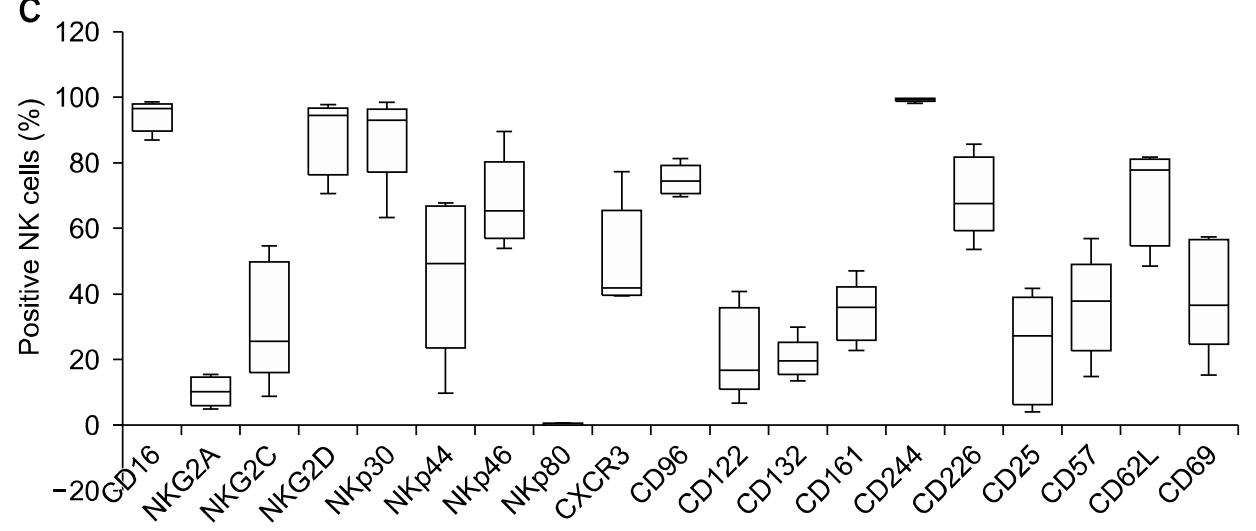

B

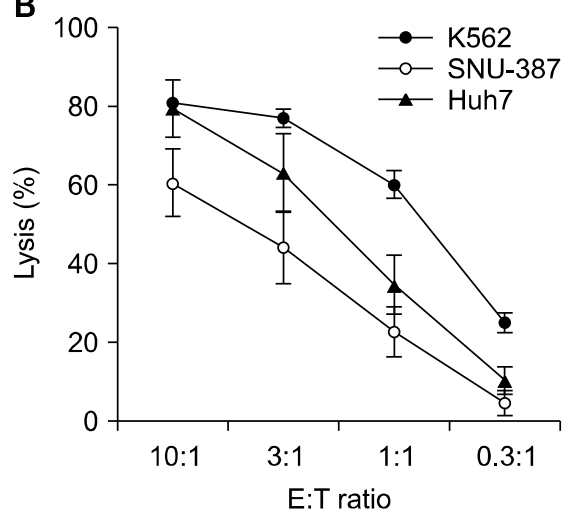

Fig. 2. Characterization of ex vivo-expanded NK cells. (A) $\mathrm{T}$ cell-depleted PBMCs from healthy donors were expanded for 14 days in the GMP-compliant facility. The percentages of $\mathrm{CD}_{16}{ }^{+} \mathrm{CD}_{56}{ }^{+}, \mathrm{CD}^{+}, \mathrm{CD} 14^{+}$, and $\mathrm{CD} 19^{+}$cells were analyzed by flow cytometric analyses. (B) Cytotoxicity of expanded NK cells against K562, SNU387 and Huh7 cell lines. Each plot represents mean \pm standard deviation (SD). (C) Immunophenotypic characterization of $\mathrm{NK}$ cells was analyzed by flow cytometric analyses. The whisker box plots show the percentage of each marker positive NK cells. All results are calculated as mean \pm SD from five different donors.

Table 2. Perioperative characteristics and outcomes

\begin{tabular}{|c|c|c|c|c|c|c|c|c|}
\hline No. & Operation & $\begin{array}{l}\text { Operatio } \\
\text { n time } \\
(\min )\end{array}$ & $\begin{array}{l}\text { Blood } \\
\text { loss } \\
(\mathrm{ml})\end{array}$ & $\begin{array}{l}\text { Tumor } \\
\text { size } \\
(\mathrm{cm})\end{array}$ & PVTT & Cirrhosis & $\mathrm{HCC}$ recurrence & Outcomes \\
\hline 1 & Lt. hepatectomy & 191 & 150 & 8.2 & Negative & Negative & Positive (liver) & Alive (49 months) \\
\hline 2 & $\begin{array}{l}\text { Laparoscopic } \\
\text { segmentectomy (S5) }\end{array}$ & 197 & 50 & 2.2 & Negative & Negative & Positive (liver) & Alive (48 months) \\
\hline 3 & $\begin{array}{l}\text { Rt. Posterior } \\
\text { sectionectomy }\end{array}$ & 235 & 600 & 5.5 & Positive & Negative & $\begin{array}{l}\text { Positive } \\
\text { (liver, lung, and } \\
\text { bone) }\end{array}$ & Dead (7 months) \\
\hline 4 & Wedge resection (S6) & 172 & 250 & 2.2 & Negative & Negative & Negative & Alive (43 months) \\
\hline 5 & Segmentectomy (S4) & 206 & 250 & 2.1 & Negative & Positive & Negative & Alive (42 months) \\
\hline
\end{tabular}

PVTT, portal vein tumor thrombosis; HCC, hepatocellular carcinoma

\section{Efficacy}

Perioperative characteristics and outcomes are outlined in Table 2. The median follow-up period was 43 months (range, 7-49 months). The RFS and OS rates at 3 years after NK cell infusion were $60 \%$ and $80 \%$, respectively (Fig. 3). Three patients were diagnosed with recurrent HCC. One patient (case 3) was diagnosed at 2 months after hepatic resection. The initial recurrence was multiple sites including liver, lung, and bone. He was dead at 7 months after liver resection because of disseminated HCC recurrence. In this patient, $\mathrm{HCC}$ recurred at 2 months after curative hepatic resection accompanied with a one-time injection of MG4101. Thus, his recurrence of HCC came before the allogenic NK cells were effective.

The second patient (case 1) was diagnosed with the first intrahepatic HCC recurrence at 7 months after curative liver resection. She was treated with RFA and lived without any further HCC recurrence for 42 months 
A

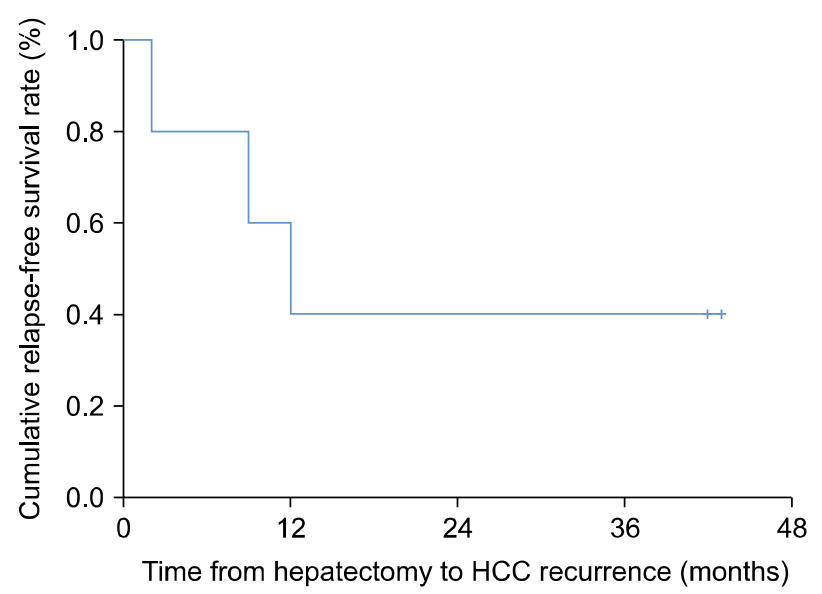

B

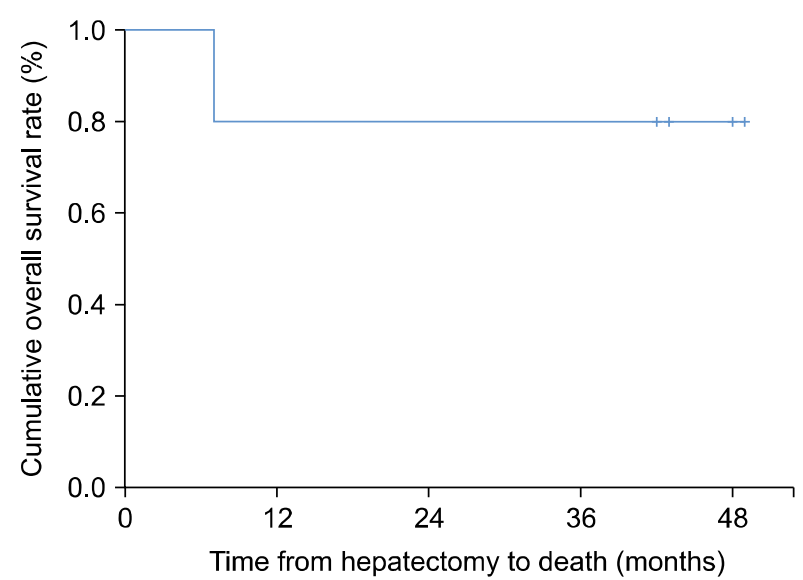

Fig. 3. RFS and OS of patients treated with MG4101 during the trial period and follow-up study.
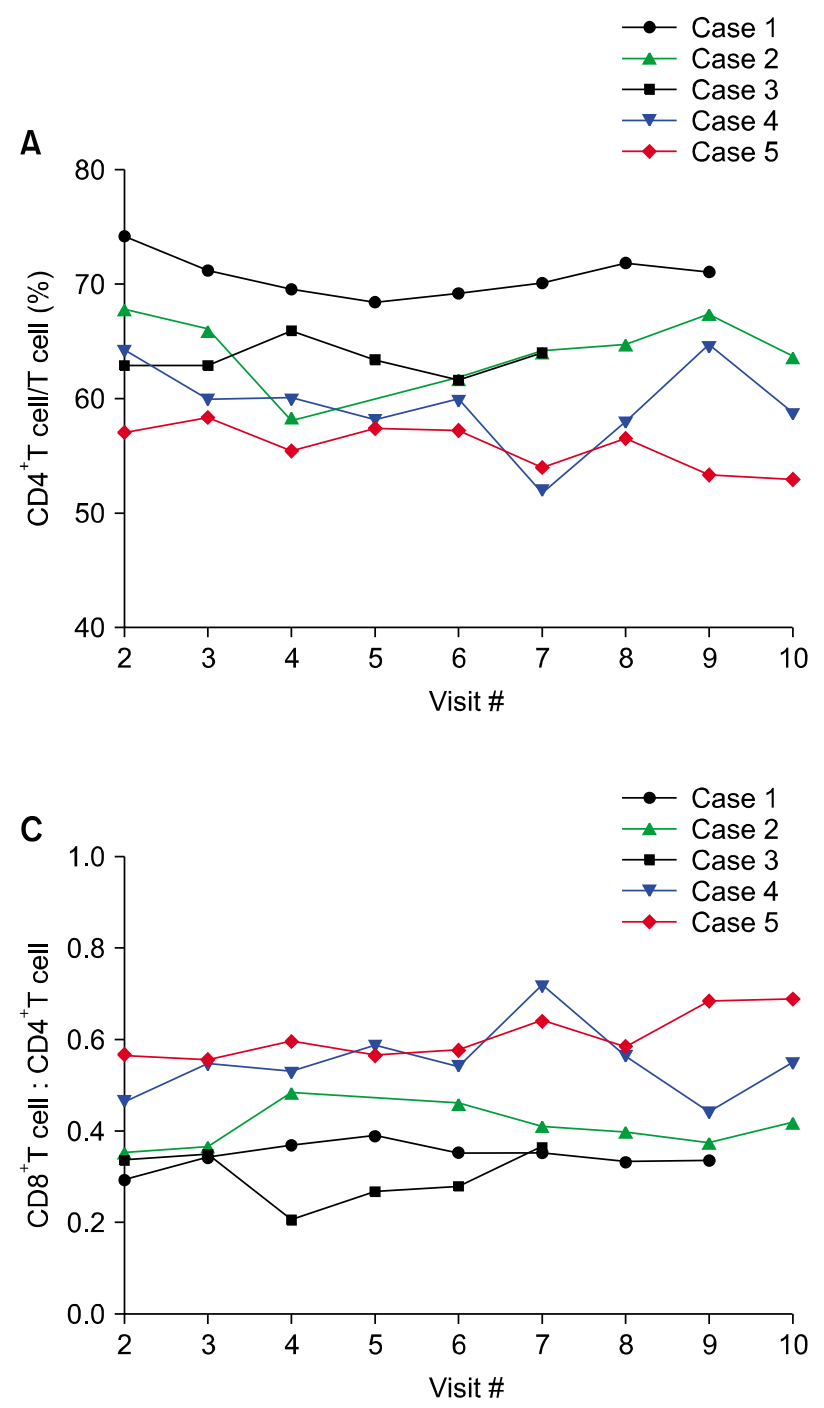

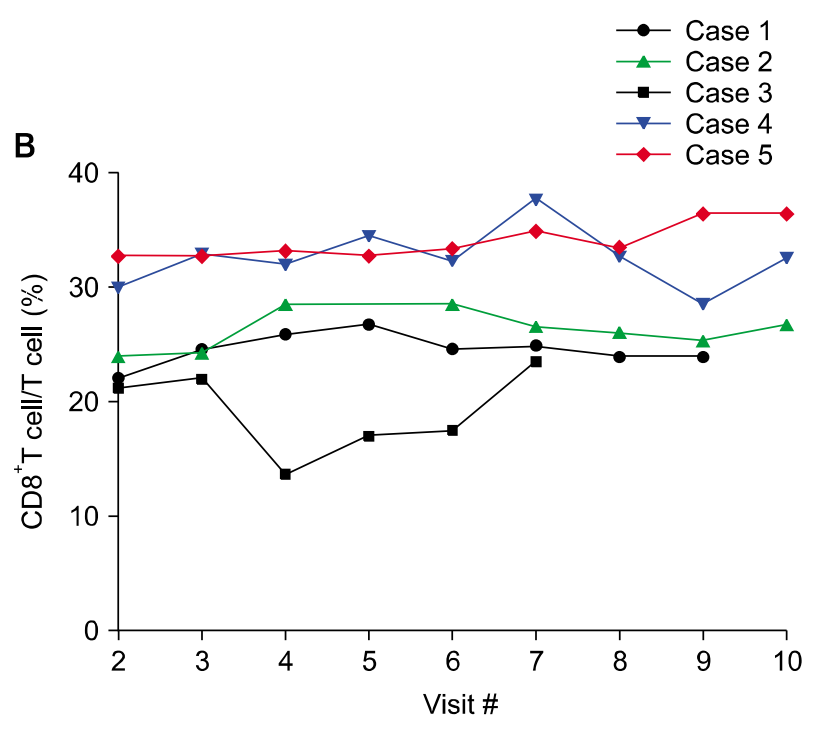

Fig. 4. Analysis of $\mathrm{T}$ cells in patient peripheral blood. The concentrations of CD4+ T cells $(\mathrm{A})$ and $\mathrm{CD} 8+\mathrm{T}$ cells $(\mathrm{B})$ were monitored for 10 weeks after MG4101 injection. A higher ratio of $\mathrm{CD} 8+/ \mathrm{CD} 4+$ was seen in patient cases 2,4 , and $5(\mathrm{C})$. 
thereafter. She had a recurrence of HCC after 5 injections of allogenic NK cells. Considering the recurrence of hepatocellular carcinoma at 7 months after surgery, it may be the case that intrahepatic metastasis was already present at the time of surgery. In the third patient (case 2), HCC recurrence was detected shortly after the study period ended.

\section{Immune monitoring}

After repeated injections of MG4101, we did not observe any critical changes in the frequency and activation status of immune cell populations, such as $\mathrm{T}$ cells, B cells, NK cells, Treg cells, monocytes, and myeloid-derived suppressor cells (MDSC) in the analysis of the blood samples derived from this clinical trial (data not shown). However, it is worth noting that the two recurrence-free patients (cases 4 and 5) showed a higher ratio of CD8+ $\mathrm{T}$ lymphocyte populations before and after MG4101 administrations compared with the three patients with recurrence (cases 1, 2, and 3) (Fig. 4).

\section{DISCUSSION}

HCC development and progression are related to chronic inflammation. ${ }^{18}$ In addition, patients with HCC demonstrate some dysfunctions in their immune system, including abnormal innate and adaptive immune responses. ${ }^{19}$ Once tumors are established, mutual interactions between tumors and immune cells present during inflammation may provide conditions favorable for tumor cell survival. ${ }^{20}$ Immune suppressor cells including regulatory $\mathrm{T}$ cells, myeloid-derived suppressive cells, or tumor-associated macrophages, may facilitate tumor immune evasion. ${ }^{21}$ If natural tumor-infiltrating lymphocytes are incompletely activated or proliferate as a slower rate, those cells fail to eradicate tumors. ${ }^{22}$ Therefore, one strategy to reduce tumor recurrence is to enhance antitumor immune responses that may induce sufficient inhibitory effects to prevent tumor cell growth and survival.

HCC is an ideal tumor for targeting by immune-based therapies. ${ }^{11-13,19}$ However, the observation of tumor progress in HCC despite the presence of tumor-specific immune responses suggests that development of HCC leads to a number of immune suppressor mechanisms. ${ }^{23,24}$

The number of NK cells in the peripheral blood of HCC patients has been published as significantly pos- itively correlated with survival rates and the prognosis of liver cancer. ${ }^{25}$ Given the fact that previous successful treatment of leukemia was achieved with alloreactive haploidentical KIR ligand-mismatched NK cells, it was expected that administration of MG4101 would be safe and exhibit enhanced clinical benefit in HCC patients over other therapies. The function of allogeneic NK cells, distinct from major MHC-restricted cytolytic activity of $\mathrm{T}$ cells, may play a role in antitumor surveillance through an MHC-unrestricted manner. Together, NK cells contribute to the induction of adaptive immune responses by secreting cytokines and chemokines. These concepts of allogeneic NK cell therapy are currently being evaluated in various phases of clinical trials for the treatment of human cancers.

In this clinical trial, we investigated the safety and efficacy of ex vivo-expanded allogenic NK cells in five patients who underwent curative liver resection as adjuvant therapy. There were no adverse drug reactions, and all patients, with the exception of one patient (case 3) with early death due to rapidly-progressing $\mathrm{HCC}$, tolerated the five scheduled injections well. This trial was not conducted using the classical designs for phase I dose-escalation toxicity trials. Experience has shown that the classic dose escalation trials for vaccine products yield little safety information. The early death patient (case 3) had poor prognostic factors such as increased tumor size, elevated AFP and PIVKA-II, and the presence of portal vein tumor thrombosis (PVTT). The high early recurrence rates of HCC patients with unfavorable characteristics such as PVTT suggest that simple tumor removal would be insufficient for microscopic intrahepatic dissemination beyond the resection field. ${ }^{26}$

Even though this was a feasibility and safety trial, not a therapeutic efficacy trial, our study showed significant observations. Ex vivo-expanded allogenic NK cell infusions demonstrated no significant toxicity, including no worsening of hepatic function and no evidence of exacerbation of $\mathrm{HBV}^{27}$ If early recurrence occurred within 1 year following HCC surgery, patient survival was lower than if recurrence was late. ${ }^{5}$ Early recurrence has been shown to be associated with tumor-related factors including large tumor size, increased number of tumors, and high AFP levels. ${ }^{5}$ Late recurrence seems to be related to background liver disease conditions such as hepatic in- 
flammation and liver damage. ${ }^{28}$ Even though two patients recurred about 1 year after curative liver resection, they survived for 48 and 49 months after surgery without HCC recurrence after RFA treatment. Although this clinical trial included a relatively small number of patients, the therapeutic effect of allogenic NK cells is likely to have a preventive effect on late recurrence that is related to background liver disease, rather than preventing early recurrence associated with tumor-related factors.

Our study reveals that infusion with allogenic NK cells may be associated with either enhanced innate immunity or the enhancement of the T-cell-mediated adaptive immune response. Many studies have shown that $\mathrm{CD} 8+\mathrm{T}$ lymphocytes in patients are incompletely activated, proliferate less vigorously and fail to eradicate tumors. ${ }^{22,29}$ Additionally, the function of NK cells in patients has been shown to be suppressed or dysfunctional. Based on the positive effect of NK cells on the induction of adaptive immune responses by several mechanisms such as secreting cytokines and chemokines, the synergistic effect of CD8+ T cells with NK cells could be proposed to have produced an appropriate anti-tumor immune response in our clinical trial. To this end, additional analysis of if ex vivo-activated NK cells mediated overcoming the less potent function of $\mathrm{CD} 8+\mathrm{T}$ cells will not only provide valuable information but may also improve efficacy in anticancer immunotherapy.

In conclusion, our study shows that patients can tolerate the administration of ex vivo-expanded allogenic NK cells as adjuvant immunotherapy after curative liver resection, without drug-related adverse events. This study not only establishes the safety and feasibility of producing ex vivo-expanded allogenic NK cells as adjuvant immunotherapy in patients with HBV-related HCC but may also provide preliminary evidence of efficacy in HCC patients after curative liver resection. Thus, expanded allogenic NK cells may be expected to produce an appropriate anti-tumor activity. In addition, the long-term safety and cost-effectiveness of adjuvant immunotherapy with ex vivo-expanded allogenic NK cells, which were not addressed in this extended follow-up study, need to be further evaluated. Further large-scale prospective randomized clinical studies are required to evaluate whether the ex vivo-expanded allogenic NK cells immunotherapy approach provides clinical benefit.

\section{DATA AVAILABILITY STATEMENT}

The datasets generated for this study are available upon request to the corresponding author.

\section{ETHICS STATEMENT}

The studies involving human participants were reviewed and approved by the Institutional Review Board of Samsung Medical Center (Seoul, Korea) (SMC-201304-019). The patients/participants provided written informed consent to participate in this study.

\section{ACKNOWLEDGEMENTS}

This work was supported by GC LabCell.

We would like to thank the patients and their families for participating in this study.

\section{CONFLICT OF INTEREST}

Sung Yoo Cho, Miyoung Jung, Jung Hyun Her, Okjae Lim, and Yu-Kyeong Hwang are GC LabCell employees. All remaining authors have declared no conflict of interest.

\section{ORCID}

Jong Man Kim: https://orcid.org/0000-0002-1903-8354

Sung Yoo Cho: https://orcid.org/0000-0001-7785-1450

Jinsoo Rhu: https://orcid.org/0000-0001-9809-8525

Miyoung Jung: https://orcid.org/0000-0003-0296-3524

Jung Hyun Her: https://orcid.org/0000-0002-1044-2430

Okjae Lim: https://orcid.org/0000-0002-8838-4496

Gyu-Seong Choi: https://orcid.org/0000-0003-2545-3105

Eui-Cheol Shin: https://orcid.org/0000-0002-6308-9503

Yu-Kyeong Hwang: https://orcid.org/0000-0001-5345-6691

Jae-Won Joh: https://orcid.org/0000-0003-4823-6218

\section{AUTHOR CONTRIBUTIONS}

Conceptualization: JMK, YKH, JWJ. Data curation: JMK, SYC, MJ, JHH, OL. Formal analysis: JMK, SYC, JR, MJ, JHH, OL. Funding acquisition: JWJ. Methodology: JMK, GSC, YKH. Project administration: JMK, YKH, JWJ. Visualization: SYC, JR, GSC, ECS. Writing - origi- 
nal draft: JMK, SYC, YKH. Writing - review \& editing: YKH, JWJ.

\section{REFERENCES}

1. Yu SJ. A concise review of updated guidelines regarding the management of hepatocellular carcinoma around the world: 2010-2016. Clin Mol Hepatol 2016;22:7-17.

2. Kim JM, Kwon CH, Joh JW, Park JB, Lee JH, Kim SJ, et al. Outcomes after curative hepatectomy in patients with non-B non-C hepatocellular carcinoma and hepatitis B virus hepatocellular carcinoma from non-cirrhotic liver. J Surg Oncol 2014; 110:976-981.

3. Kim JM, Kwon CH, Joh JW, Park JB, Lee JH, Kim SJ, et al. Differences between hepatocellular carcinoma and hepatitis B virus infection in patients with and without cirrhosis. Ann Surg Oncol 2014;21:458-465.

4. Kim JM, Yi NJ, Kwon CHD, Lee KW, Suh KS, Joh JW. Early disseminated recurrence after liver resection in solitary hepatocellular carcinoma. Ann Surg Treat Res 2018;94:129-134.

5. Jung SM, Kim JM, Choi GS, Kwon CHD, Yi NJ, Lee KW, et al. Characteristics of early recurrence after curative liver resection for solitary hepatocellular carcinoma. J Gastrointest Surg 2019;23:304-311.

6. Samuel M, Chow PK, Chan Shih-Yen E, Machin D, Soo KC. Neoadjuvant and adjuvant therapy for surgical resection of hepatocellular carcinoma. Cochrane Database Syst Rev 2009;2009: CD001199.

7. Bruix J, Takayama T, Mazzaferro V, Chau GY, Yang J, Kudo $\mathrm{M}$, et al. Adjuvant sorafenib for hepatocellular carcinoma after resection or ablation (STORM): a phase 3, randomised, doubleblind, placebo-controlled trial. Lancet Oncol 2015;16:1344-1354.

8. Heimbach JK, Kulik LM, Finn RS, Sirlin CB, Abecassis MM, Roberts LR, et al. AASLD guidelines for the treatment of hepatocellular carcinoma. Hepatology 2018;67:358-380.

9. European Association for the Study of the Liver. Electronic address: easloffice@easloffice.eu; European Association for the Study of the Liver. EASL Clinical Practice Guidelines: Management of hepatocellular carcinoma. J Hepatol 2018;69:182-236.

10. Korean Liver Cancer Study Group (KLCSG); National Cancer Center, Korea (NCC). 2014 KLCSG-NCC Korea Practice Guideline for the management of hepatocellular carcinoma. Gut Liver 2015; 9:267-317.

11. Lee JH, Lee JH, Lim YS, Yeon JE, Song TJ, Yu SJ, et al. Adjuvant immunotherapy with autologous cytokine-induced killer cells for hepatocellular carcinoma. Gastroenterology 2015;148: 1383-1391.e6.

12. Yu R, Yang B, Chi X, Cai L, Liu C, Yang L, et al. Efficacy of cytokine-induced killer cell infusion as an adjuvant immunotherapy for hepatocellular carcinoma: a systematic review and meta-analysis. Drug Des Devel Ther 2017;11:851-864.

13. Lee JH, Lee JH, Lim YS, Yeon JE, Song TJ, Yu SJ, et al. Sustained efficacy of adjuvant immunotherapy with cytokine-in- duced killer cells for hepatocellular carcinoma: an extended 5-year follow-up. Cancer Immunol Immunother 2019;68:23-32.

14. Moretta A, Pende D, Locatelli F, Moretta L. Activating and inhibitory killer immunoglobulin-like receptors (KIR) in haploidentical haemopoietic stem cell transplantation to cure high-risk leukaemias. Clin Exp Immunol 2009;157:325-331.

15. Lim O, Jung MY, Hwang YK, Shin EC. Present and future of allogeneic natural killer cell therapy. Front Immunol 2015;6:286.

16. Yang Y, Lim O, Kim TM, Ahn YO, Choi H, Chung H, et al. Phase I study of random healthy donor-derived allogeneic natural killer cell therapy in patients with malignant lymphoma or advanced solid tumors. Cancer Immunol Res 2016;4:215-224.

17. Lim O, Lee Y, Chung H, Her JH, Kang SM, Jung MY, et al. GMP-compliant, large-scale expanded allogeneic natural killer cells have potent cytolytic activity against cancer cells in vitro and in vivo. PLoS One 2013;8:e53611.

18. Grivennikov SI, Greten FR, Karin M. Immunity, inflammation, and cancer. Cell 2010;140:883-899.

19. Hong YP, Li ZD, Prasoon P, Zhang Q. Immunotherapy for hepatocellular carcinoma: from basic research to clinical use. World J Hepatol 2015;7:980-992.

20. Ungefroren H, Sebens S, Seidl D, Lehnert H, Hass R. Interaction of tumor cells with the microenvironment. Cell Commun Signal 2011;9:18.

21. Zamarron BF, Chen W. Dual roles of immune cells and their factors in cancer development and progression. Int J Biol Sci 2011;7:651-658.

22. Korangy F, Höchst B, Manns MP, Greten TF. Immune responses in hepatocellular carcinoma. Dig Dis 2010;28:150-154.

23. Harding JJ, El Dika I, Abou-Alfa GK. Immunotherapy in hepatocellular carcinoma: primed to make a difference? Cancer 2016;122:367-377.

24. Aerts M, Benteyn D, Van Vlierberghe H, Thielemans K, Reynaert H. Current status and perspectives of immune-based therapies for hepatocellular carcinoma. World J Gastroenterol 2016;22:253-261.

25. Chew V, Chen J, Lee D, Loh E, Lee J, Lim KH, et al. Chemokine-driven lymphocyte infiltration: an early intratumoural event determining long-term survival in resectable hepatocellular carcinoma. Gut 2012;61:427-438.

26. Lim KC, Chow PK, Allen JC, Chia GS, Lim M, Cheow PC, et al. Microvascular invasion is a better predictor of tumor recurrence and overall survival following surgical resection for hepatocellular carcinoma compared to the Milan criteria. Ann Surg 2011;254:108-113.

27. Kim JM, Kwon CH, Joh JW, Park JB, Lee JH, Kim SJ, et al. PIVKA-II is a useful marker in patients with modified UICC T3 stage hepatocellular carcinoma. Hepatogastroenterology 2013;60: 1456-1462.

28. Imamura H, Matsuyama $\mathrm{Y}$, Tanaka E, Ohkubo T, Hasegawa K, Miyagawa $\mathrm{S}$, et al. Risk factors contributing to early and late phase intrahepatic recurrence of hepatocellular carcinoma after hepatectomy. J Hepatol 2003;38:200-207.

29. Zarour HM. Reversing T-cell dysfunction and exhaustion in cancer. Clin Cancer Res 2016;22:1856-1864. 